\title{
Shared representation of passives across Scottish Gaelic and English: evidence from structural priming
}

\author{
Timea Kutasi - Ellise Suffill • Catriona L. Gibb • Antonella Sorace • \\ Martin J. Pickering • Holly P. Branigan $(D)$
}

Received: 27 February 2018/Revised: 15 April 2018/Accepted: 16 April 2018/Published online: 10 May 2018

(C) The Author(s) 2018

\begin{abstract}
Evidence from cross-linguistic priming suggests that bilinguals can share their representations of constructions that occur in both languages. Some studies suggest that such sharing occurs only when the constructions involve identical syntactic categories and word order, thereby supporting a restricted sharedstructure account of bilingual linguistic representation. But other studies suggest that such exact repetition is not necessary for priming. To address this question, we conducted an experiment in which bilingual speakers of Scottish Gaelic and English heard Gaelic utterances involving actives, two types of passives, or noun phrase conjunctions (as a baseline), and then produced English transitive descriptions. Their target descriptions tended to use the same construction as the prime utterances. As both active and passive word order differs between Gaelic and English, the results support a less restricted sharedstructure account of bilingual linguistic representation.
\end{abstract}

Timea Kutasi and Ellise Suffill are joint first authors.

T. Kutasi - E. Suffill - C. L. Gibb - M. J. Pickering ·

H. P. Branigan $(\bowtie)$

Department of Psychology, University of Edinburgh, Edinburgh, UK

e-mail: Holly.Branigan@ed.ac.uk

\section{A. Sorace}

Department of Linguistics and English Language,

University of Edinburgh, Edinburgh, UK
Keywords Blingualism - Cross-linguistic priming · Language production $\cdot$ Scottish Gaelic $\cdot$ Structural priming $\cdot$ Syntax

\section{Introduction}

Traditional cognitive science has largely concentrated on a group of people who are not particularly representative of the world as a whole. One aspect of this narrow perspective is that studies of how people represent and process language has focused on monolinguals (i.e., typically English-speaking), or has developed theories of monolingualism even if the participants in the experiments actually speak multiple languages. Of course, interest in bilingualism (and multilingualism) has greatly increased in recent years, but even then the emphasis is on speakers of Germanic or Romance languages, or occasionally of other dominant (majority) languages such as Mandarin Chinese, Japanese, or Russian. A goal of cultural cognitive science is to present theories that draw on people from minority cultures, and an important way to develop such theories is to investigate the way that their bilingualism impacts on their cognitive processes.

In this paper, we consider the representation and processing of linguistic information in bilingual speakers of Scottish Gaelic and English. Scottish 
Gaelic (henceforth, Gaelic) is a language of the Goidelic branch of the Celtic language family, which itself is a branch of Indo-European, and is most closely related to Irish, Manx, and Canadian Gaelic (see Lamb 2001). According to the Scotland's 2011 Census Office for National Statistics (2016), there are 57,000 fluent speakers (1.1\% of the population), largely living in the Hebrides (and some areas of the Highlands). All speakers (of school age and above) are bilingual with English. These speakers' vocabulary and grammar differ considerably, depending for example on dialect, age, or whether people were taught using GaelicMedium Education, and so our participants may not be representative of all Gaelic speakers.

In this paper, we consider the extent to which bilinguals share information between their languages. There is strong evidence for parallel activation of bilinguals' two lexicons (e.g., Kroll and Ma 2018). More importantly, there also appears to be parallel activation of syntactic (grammatical) knowledge, as we shall see. But does such parallel activation occur when the languages are very different from each other? We can investigate this question using bilingual speakers of Gaelic and English, as the languages are typologically very different; for example, Gaelic has the basic word order VSO (Verb-Subject-Object) rather than SVO (Subject-Verb-Object).

Structural priming between languages and its limitations

It is well known that speakers tend to repeat their own or other people's constructions within a language (Bock 1986; Branigan et al. 2000)—a phenomenon known as structural (or syntactic) priming. For example, Bock (1986) showed that people were more likely to describe a picture using an English passive if they had just used an English passive to describe an unrelated picture than if they had just used an English active for that purpose. Such priming has been demonstrated for many languages and constructions even when the sentences are otherwise unrelated (Pickering and Ferreira 2008). In particular, these findings support the representation of abstract structures such as the passive (Branigan and Pickering 2017).

In the same way, priming can be informative about the sharing of abstract structures across languages. Hartsuiker et al. (2004) found that Spanish-English bilinguals tended to produce an English passive more frequently after a Spanish passive (e.g., El camion es perseguido por el taxi, "The truck is chased by the taxi") than after a Spanish active (El taxi persigue el camion, "The taxi chases the truck"). Importantly, these transitive constructions in Spanish have the same form as in English, with both passives having a noun phrase specifying the agent, an auxiliary verb, a past participle, and a prepositional phrase specifying the patient, and both actives having a noun phrase specifying the agent, a main verb, and a noun phrase specifying the patient.

Does cross-linguistic priming require such repetition of constituents and constituent order? Some studies suggest that this is the case. Loebell and Bock (2003) found cross-linguistic priming between English and German datives (which share word order), but not between transitives (which do not share word order, as the German passive has the past participle at the end of the sentence). Bernolet et al. (2007) found that participants were primed to describe a red shark as de haai die rood is ("The shark that red is") rather than de rode haai ("The red shark") after a similar description in German (which shares adjective-verb word order with Dutch), but not after a similar description in English. Finally, Salamoura and Williams (2007) found that dative priming from Greek to English was dependent on word-order repetition.

In contrast, other studies have found priming in the absence of word-order repetition. For example, Shin and Christianson (2009) found priming of two types of dative sentences across languages in Korean-English bilinguals, even though the verb occurs sentencefinally in Korean, but not in English. However, a third type of dative did not show priming effects. Bernolet et al. (2009) found that Dutch-English bilinguals tended to produce passives after Dutch passives with the same word order as English, but also after Dutch passives in which the prepositional phrase occurred before the verb. This latter study is particularly important because it suggests that the passive construction (rather than simply the order of constituents) may be primed and hence represented. But given the complexity of previous findings, it would be important to determine whether priming occurs for actives and passives that differ greatly in their structure across languages, using two languages that are not closely related. 
Scottish Gaelic does not have a single type of passive, but rather several constructions in which the patient is emphasized and the agent demoted, and which meet other criteria associated with passivehood (see Payne 1997). The two constructions that appear to correspond most closely to the English passive are what we call the be-passive (1a) and the go-passive (1b). The be-passive emphasizes the current state, and has a roughly adjectival interpretation due to the aspectual particle air (Adger 2007). The gopassive is "non-agentive" and conveys the meaning "come to pass", in which emphasis is placed on the event using the (suppletive) auxiliary rach ("to go"). It can have an eventive or adjectival interpretation (the latter occurring when the agent is omitted).

1a. Tha an uinneag air a bristeadh.

Be the window ASP 3FS break-VN.

"The window has been broken" (i.e., emphasis on its current state).

1b. Chaidh an uinneeag a bristeadh. Went the window PRT break-VN.

"The window was/got broken" (i.e., emphasis on the act leading to the current state).

Note. ASP: aspect; 3FS: Third person-femininesingular; VN: verbal noun; PRT: preterite.

It should be clear that neither construction is particularly similar in lexical or syntactic terms to the English passive. In both cases, the word order is of course different from English. In addition, the bepassive involves a particle air that has no correspondence in English, whereas the go-passive involves a verb (Chaidh, "went") that is not used in English. If priming requires close repetition between languages, then neither construction should prime the production of English passives. But if such close repetition is not needed, then one or both constructions may serve as effective primes. Note also that active sentences have different word orders in Gaelic and English, and so priming between Gaelic and English actives is similarly only possible if priming does not require close repetition.

To investigate these issues, we conducted a crosslinguistic structural priming study in which EnglishGaelic participants read Gaelic be- and go-passives, as well as actives and conjoined noun phrases (as baselines), and investigated whether such utterances primed their subsequent production of English descriptions of transitive events. If priming requires close repetition, then the form of the Gaelic prime should not affect the form of the English description.

But if priming does not require close repetition, then the form of the Gaelic prime might affect the form of the English description. We assume that any such priming would be localized to passives (as priming of highly frequent constructions such as actives does not typically occur), but we made no assumption about whether priming would occur with be-passives, gopassives, or both. We used conjoined noun phrases as baselines because they did not involve a verb (hence would be unrelated to any of the experimental conditions) but did involve two entities (as in the experimental conditions).

We used items in which prime and target referred to unrelated events, and hence would not involve translation-equivalent verbs. Although such meaning repetition can enhance priming (Schoonbaert et al. 2007), an experiment using translation-equivalent verbs would not allow us to draw general conclusions about the relationship between transitive constructions across languages.

\section{Experiment}

\section{Participants}

Twenty-two English-Gaelic bilinguals aged $15-18$ years $(M=16.31 ; \quad S D=0.03)$ from two schools participated in the study (15 females). All participants reported English as their dominant language and were fluent in Gaelic. All participants had been exposed to Gaelic from birth, with most learning Gaelic and English simultaneously, excluding one participant who considered Gaelic to be her first language. A fluent Gaelic speaker from the University of Edinburgh (who was judged to have a neutral accent) recorded the prime sentences. Participants completed a questionnaire that included the information reported in Table 1. All participants scored a mean of above 4.5 (out of 7) across listening, speaking, reading, and writing in Gaelic $(M=5.69, \mathrm{SD}=0.62)$. They also carried out an English-Gaelic and GaelicEnglish translation test involving 15 English sentences and 15 Gaelic sentences adapted from Dorian's (1981) 
Table 1 Participants' profile, language experience, and proficiency by self-report in Gaelic

\begin{tabular}{lr}
\hline Variables & Means (SD) \\
\hline Age at testing (years) & $16.31(0.03)$ \\
Age when began acquiring Gaelic (years) & $3.09(1.57)$ \\
Gaelic conversation frequency (1-4 pt scale) & $3.40(0.50)$ \\
Speaking proficiency (1-7 pt scale) & $5.50(1.00)$ \\
Listening proficiency (1-7 pt scale) & $6.55(0.51)$ \\
Writing proficiency (1-7 pt scale) & $5.23(0.97)$ \\
Reading proficiency (1-7 pt scale) & $5.50(0.90)$ \\
English-Gaelic translation (/60) & $45.05(6.69)$ \\
Gaelic-English translation $(/ 60)$ & $55.14(7.35)$ \\
\hline
\end{tabular}

elicitation task, in which 2 marks were awarded for grammar and 2 marks were awarded for vocabulary.

Items

To determine how English-Gaelic bilinguals perceived and used be- and go-passives, 28 further participants (ages: 14-79; 27 with English as L1, 1 with Dutch as L1; mean age at beginning of Gaelic acquisition: 13.30 years) provided ratings for a bepassive (Bha am manach air a bhuaileadh leis an tidsear), a go-passive (Chaidh am manach a bhuaileadh leis an tidsear), and an English translation (The monk was hit by the teacher) as presented in a questionnaire. Nine participants rated the be-passive as having a more similar meaning to the English translation, 10 rated the go-passive as more similar, and 9 rated them as equally similar; 6 rated the bepassive as more commonly used, 14 rated the gopassive as more commonly used, and 8 rated them equally; 8 said the be passive was learned first, 9 said the go-passive was learned first, and 7 said they were learned at the same time (with 4 participants not responding). Pearson's Chi square tests (implemented in R; R Core Team 2015) revealed no differences between the sentence ratings. Importantly, the results of the questionnaire provide no reason to assume that any differences in priming between the two types of passive would be due to differences in meaning.

We created 32 items, which consisted of prime sentences, prime pictures, and target pictures. There were four versions of each prime sentence, corresponding to the four experimental conditions: 2a. Baseline (BL)

Am poileas agus am meirleach.

ART policeman and ART thief

"The policeman and the thief."

2b. Active (A)

"The policeman caught the thief."

Ghlac a' poileas am meirleach.

catch-PAST ART policeman ART thief.

2c. be-passive (BE)

Bha am meirleach air a ghlacadh leis a' poileas.

Be ART thief ASP ART catch-VN by ART policeman

"The thief was caught by the policeman."

2d. go-passive (GO)

Chaidh am meirleach a ghlacadh leis a' poileas. Went ART thief ART catch-VN by ART policeman

"The thief went (got) caught by the policeman."

Note. PAST: past tense; ART: article; ASP: aspect; $\mathrm{VN}$ : verbal noun.

Both prime and target pictures depicted an event involving two entities. In the active, $b e$ - passive, and go-passive conditions, they also contained one of eight verbs compatible with the event (in Gaelic for the prime pictures, and in English for the target pictures); in the baseline condition, the target picture included a verb but the prime picture did not. The patient always occurred on the left (as this increases participants' tendency to produce passives; Bock and Griffin 2000). The prime pictures involved two human entities.

In the item set as a whole, three-quarters of the prime pictures matched the Gaelic prime sentences; the remainder differed in one of the entities or the action depicted. The target pictures involved a human patient and either an inanimate agent (8 pictures; e.g., an ambulance hitting a doctor) or an animal agent (24 pictures; e.g. a mouse lifting a pirate). This design rules out an explanation of any priming effect that makes reference to animacy or humanness, for example a tendency to repeat the animacy of the subject (cf. Bock et al. 1992). The prime and target pictures always depicted different entities and a different action.

There were also 67 filler items (134 pictures) involving a 'prime' picture of one or more non- 
interacting objects (e.g., a policeman), a 'prime' simple NP (e.g., am poileas 'a policeman'), and a 'target' picture (e.g., two apples). We assigned the items to four lists such that each list contained one version of each item and eight versions from each condition (i.e., in a Latin-Square design), and the lists were individually randomized.

\section{Procedure}

The experiment was implemented in E-Prime 2.0 software (Psychology Software Tools, Pittsburgh, PA). Participants were tested in a quiet environment and wore a headset with a microphone. Before starting the task, the experimenter told the participants that they would take part in a picture-matching task, in which they would hear picture descriptions recorded from a previous participant. Instructions were given in English both orally and onscreen at the start of the experiment. Firstly, participants were familiarized with the characters that featured in the stimuli. The participants were told there was no need to remember the names, but that they should remember the characters. They then took part in a practice block of seven trials (i.e., three filler trials and one trial of each prime type) and then had the opportunity to ask questions. Each trial started with the prompt Eist ("listen" in Gaelic) for $1500 \mathrm{~ms}$. A recorded Gaelic sentence was then played, after which a picture appeared, with a verb at the bottom in Gaelic. The participants pressed a button to indicate whether the picture matched the recorded sentence. The prompt Describe in English then appeared for $1500 \mathrm{~ms}$. Next, the target picture appeared with a verb provided at the bottom in English. After describing the picture in English, participants pressed the space bar to proceed to the next trial (see Fig. 1).

\section{Results}

A description was scored as an active if it contained the agent as the sentence subject, the main verb, and the patient as the direct object, in that order. It was scored as a passive if it contained the patient as the sentence subject, the verb, the preposition by, and the agent, in that order. All other responses were scored as an other response.

Performance on the picture-matching task was high (mean: 90\%). Overall, participants produced 704 English sentences, of which 40 were passives $(5.71 \%$ ) (see Table 2 for the proportion of passives produced by Prime type).

We conducted a generalized logistic mixed-modelling analysis, in which each participant's responses on critical trials were entered as binomial data [i.e., if a participant produced a passive response, it was coded as ' 1 ', if not (i.e., the participant produced an active or other response), it was coded as ' 0 ']. This binomial data was compared across the prime types (i.e., BL, A,
Fig. 1 Example experimental trial

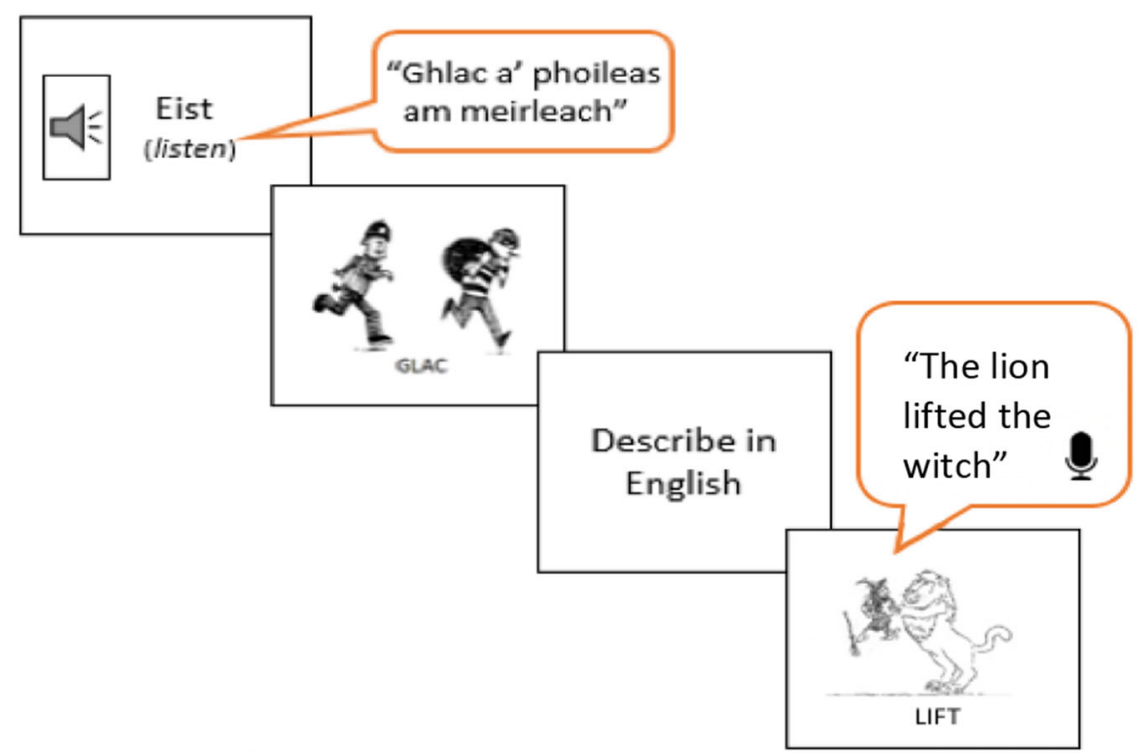


Table 2 Proportion of passives produced (as a proportion of all responses in that condition) across all participants following each prime type

\begin{tabular}{lllll}
\hline & Baseline & Active & BE-passive & GO-passive \\
\hline Proportion of passives & 0.03 & 0.03 & 0.06 & 0.10 \\
\hline
\end{tabular}

$\mathrm{BE}$, or GO). A by-subjects, by-items analysis was conducted in R using the 'Ime4' package, version 1.18 (Bates et al. 2013). Models included random intercepts for subjects and items. Our predictors were Prime type, Gaelic proficiency (i.e., mean score for self-rated listening, speaking, reading, and writing; scored as 1-7), and Exposure to Gaelic (i.e., $1=$ exposed at home, $0=$ not exposed at home). The Baseline condition was treated as the reference level. A backwards stepwise elimination approach was used to select predictors.

A full model including all predictors and a threeway interaction did not significantly improve model fit over the null model. Removing the interaction between Exposure to Gaelic and the other two predictors did not significantly decrease model fit $(p>0.05)$, neither did removing the predictor itself $(p>0.05)$. This left a model with the predictors Prime type and Proficiency (see Tables 3,4). Removing the

Table 3 Beta, standard errors, $\mathrm{z}$ values and $\mathrm{p}$ values for prime type and proficiency on number of passives produced

\begin{tabular}{lrlll}
\hline Fixed effects & \multicolumn{1}{l}{$\beta$} & SE & \multicolumn{1}{l}{$z$} & $p$ \\
\hline Intercept & -10.83 & 3.41 & -3.175 & 0.002 \\
PrimeType (A) & -0.20 & 0.65 & -0.31 & 0.76 \\
PrimeType (BE) & 0.68 & 0.57 & 1.20 & 0.23 \\
PrimeType (GO) & 1.27 & 0.53 & 2.37 & 0.02 \\
Proficiency & 8.36 & 3.96 & 2.11 & 0.03 \\
\hline
\end{tabular}

Model fit by ML

Table 4 Variance for random effects

\begin{tabular}{lll}
\hline Random effects & \\
\hline Item & Intercept & $0.13(0.36)$ \\
Subject & Intercept & $1.05(1.03)$ \\
\hline
\end{tabular}

Model fit by ML

No. of observations $=704$ interaction term between these two predictors did not significantly decrease model fit $(p>0.05)$. However, removing either Prime type $\left(X^{2}(3)=8.71, p=0.03\right)$ or Proficiency significantly reduced model fit $\left(X^{2}(1)=5.01, p=0.03\right)$. Therefore, the model of best fit included Prime type and Proficiency as predictors. This model was a significantly better fit of the data than the null model $\left(X^{2}(4)=13.71, p<0.01\right)$. Under this model, participants produced significantly more passives after a go-passive than after a baseline prime, but did not produce significantly more passives after a be-passive than after a baseline prime. There was also a significant effect of Proficiency, such that higher proficiency in Gaelic predicted a greater production of passives in English.

\section{Discussion}

In our experiment, English-Gaelic bilinguals heard transitive sentences in Gaelic and tended to repeat the structure of those sentences when subsequently producing English transitive sentences: The tendency to produce English passives was affected by whether the prime sentence was a Gaelic be- or go-passive, active, or non-transitive baseline. Such cross-linguistic priming occurred even though the word order of the Gaelic sentences was different from their English equivalents (and occurred between unrelated sentences with verbs that were not translations of each other).

These results therefore suggest that cross-linguistic structural priming does not require word-order repetition, in accord with studies such as Bernolet et al. (2009) and Shin and Christianson (2009), but in contrast to other studies such as Loebell and Bock (2003), Bernolet et al. (2007), and Salamoura and Williams (2007). Bernolet et al. (2009) found that transitive priming does not require word order repetition, and we found equivalent results for languages that are less closely related than English and Dutch. The word order in Gaelic transitives (and indeed in 
Gaelic more generally) differs fundamentally from English with respect to the position of the verb, yet cross-linguistic priming still occurs.

We therefore propose that Gaelic and English share some representations associated with "active" and "passive" sentences. Such representations are presumably more abstract than constructions (Goldberg, 1995), as be- and go-passives in Gaelic have sufficiently different meanings that they correspond to different constructions (cf. the dative alternation in English). The shared representations might correspond to agent- versus patient-focusing, an explanation that would be compatible with the finding that OVS sentences in Polish prime passives in English (Fleischer et al. 2012). However, a full investigation of the locus or loci of priming would require extensive experimentation.

Note that the pairwise comparisons demonstrate that go-passives prime English passives, but do not demonstrate that be-passives prime English passives. This lack of priming should be treated with caution (in part because of the relatively small number of passives produced overall). But overall the study provides some evidence for similarity between go-passives and English passives. Priming therefore does not seem to depend on having the same auxiliary verb across languages (because gopassive priming occurred even though the verb chaidh means "go" rather than "be"). We know that cross-linguistic priming does not require primes and targets to involve main verbs that are translation equivalents (e.g., Schoonbaert et al. 2007), and this study suggests that auxiliary verbs need not be translation equivalents either.

If priming does not occur between Gaelic bepassives and English passives, then it may relate to the fact that the be-passive has the aspectual particle air which has no correspondence in English. This finding would not straightforwardly fit with Bock's (1989) finding that priming occurs irrespective of closed-class repetition (Bock, 1989). But note that prime and target differ in the presence of a particle (air) rather than the repetition of one or other preposition (e.g., to or for), and it may be that the presence of air means that prime and target have sufficiently different constituent structure to preclude priming. Clearly, we cannot be certain whether such an explanation is correct or whether we have simply failed to detect a priming effect involving be-passives.
The experiment also revealed an effect of proficiency, with participants who were more proficient in Gaelic producing more passives in English. It may be that some participants were generally linguistically sophisticated and this was reflected both in their proficiency in Gaelic and their tendency to use a relatively uncommon English construction. Alternatively, proficient Gaelic users may have encountered many Gaelic passives, which had a long-term role in enhancing use of English passives (in a way presumably related to priming and hence particularly to experience of go-passives). Note that the effect of proficiency does not demonstrate any effect of proficiency on priming, and so we cannot conclude that proficiency affects the degree to which representations are integrated across languages (cf. Bernolet et al. 2013). Of course, our participants were quite homogenous in terms of age, learning environment, and selfrated proficiency, and further work is needed to investigate this issue.

In conclusion, we have reported a study showing cross-linguistic priming between two distantly related languages with extensive differences in word order, and have used the findings to support the sharing of linguistic representations in bilinguals. More generally, our study is an example of an investigation of a minority language that is very different from the languages that have been the focus of the great majority of psycholinguistics, and therefore constitutes an example of cultural cognitive science.

Acknowledgements This research received funding from the European Union's Seventh Framework Programme for research, technological development and demonstration under Grant agreement no. 613465 .

Open Access This article is distributed under the terms of the Creative Commons Attribution 4.0 International License (http:// creativecommons.org/licenses/by/4.0/), which permits unrestricted use, distribution, and reproduction in any medium, provided you give appropriate credit to the original author(s) and the source, provide a link to the Creative Commons license, and indicate if changes were made.

\section{References}

Adger, D. (2007). Three domains of finiteness: A minimalist perspective. In Irina Nikolaeva (Ed.), Finiteness: Theoretical and empirical foundations (pp. 23-58). Oxford: Oxford University Press. 
Bates, D., Maechler, M., Bolker, B., \& Walker, S. (2014). lme4: Linear mixed-effects models using Eigen and S4. R package version, 1(7), 1-23.

Bernolet, S., Hartsuiker, R. J., \& Pickering, M. J. (2007). Shared syntactic representations in bilinguals: Evidence for the role of word-order repetition. Journal of Experimental Psychology. Learning, Memory, and Cognition, 33(5), 931-949.

Bernolet, S., Hartsuiker, R. J., \& Pickering, M. J. (2009). Persistence of emphasis in language production: A cross-linguistic approach. Cognition, 112(2), 300-317.

Bernolet, S., Hartsuiker, R. J., \& Pickering, M. J. (2013). From language-specific to shared syntactic representations: The influence of second language proficiency on syntactic sharing in bilinguals. Cognition, 127(3), 287-306.

Bock, J. K. (1986). Syntactic persistence in language production. Cognitive Psychology, 18, 355-387.

Bock, K. (1989). Closed-class immanence in sentence production. Cognition, 31(2), 163-186.

Bock, K., \& Griffin, Z. M. (2000). The persistence of structural priming: Transient activation or implicit learning? Journal of Experimental Psychology: General, 129(2), 177.

Bock, K., Loebell, H., \& Morey, R. (1992). From conceptual roles to structural relations: Bridging the syntactic cleft. Psychological Review, 99(1), 150-171.

Branigan, H. P., \& Pickering, M. J. (2017). An experimental approach to linguistic representation. Behavioral and Brain Sciences, 40, e282.

Branigan, H. P., Pickering, M. J., \& Cleland, A. A. (2000). Syntactic co-ordination in dialogue. Cognition, 75(2), B13-B25.

Dorian, N. C. (1981). Language death: The life cycle of a Scottish Gaelic dialect. Philadelphia: University of Pennsylvania Press.

Fleischer, Z., Pickering, M. J., \& McLean, J. F. (2012). Shared information structure: Evidence from cross-linguistic priming. Bilingualism: Language and Cognition, 15(3), $568-579$.

Goldberg, A. E. (1995). Constructions: A construction grammar approach to argument structure. Chicago: University of Chicago Press.

Hartsuiker, R. J., Pickering, M. J., \& Veltkamp, E. (2004). Is syntax separate or shared between languages? Cross-linguistic syntactic priming in Spanish-English bilinguals. Psychological Science, 15(6), 409-414.

Kroll, J. F., \& Ma, F. (2018). The bilingual lexicon. In E. M. Fernández \& H. S. Cairns (Eds.), The handbook of psycholinguistics (pp. 294-319). Hoboken: Wiley.

Lamb, W. (2001). Scottish Gaelic. Munich: Lincom Europa.

Loebell, H., \& Bock, K. (2003). Structural priming across languages. Linguistics, 41, 791-824.

Office for National Statistics. (2016). 2011 Census aggregate data. http://dx.doi.org/10.5257/census/aggregate-2011-1.

Payne, T. E. (1997). Describing morphosyntax: A guide for field linguists. Cambridge: Cambridge University Press.

Pickering, M. J., \& Ferreira, V. S. (2008). Structural priming: A critical review. Psychological Bulletin, 134(3), 427-459.

R Core Team. (2015). R: A language and environment for statistical computing. The $R$ foundation for statistical computing, Vienna. http://www.R-project.org/.

Salamoura, A., \& Williams, J. N. (2007). Processing verb argument structure across languages: Evidence for shared representations in the bilingual lexicon. Applied Psycholinguistics, 28(4), 627-660.

Schoonbaert, S., Hartsuiker, R. J., \& Pickering, M. J. (2007). The representation of lexical and syntactic information in bilinguals: Evidence from syntactic priming. Journal of Memory and Language, 56(2), 153-171.

Shin, J. A., \& Christianson, K. (2009). Syntactic processing in Korean-English bilingual production: Evidence from cross-linguistic structural priming. Cognition, 112(1), 175-180. 